\title{
When Cities Become Smart, Is There Still Place for Trust?
}

Esther Keymolen*

Human beings are social beings. This means that we have to find ways to live together, cooperate, and distribute the limited resources available. This is far from easy. We cannot be sure if others will share our point of view. They might think differently about what is important and their interests will not necessarily align with ours. This uncertainty inherent in social interaction would be unbearable if we were not able to develop some basic sense of trust. We need to feel assured that others will act in character and that the ways of the world will not change overnight. Without trust, social life would simply halt. We would be overwhelmed, paralysed even, by all the unpredictable turns fate could take.

While trust might well be at the heart of social life, it does not let itself be pinned down easily. Depending on one's disciplinary lens, different aspects of trust may come to the fore. For economists a risk-benefit analysis might be an important element of trust, whereas for psychologists trust is closely linked to the relation a child is able to develop with its caregivers. Notwithstanding these domain-specific differences, there are some basic concepts and ideas that we need in order to talk about trust in a meaningful way.

First of all, trust is inherently connected to vulnerability. There has to be something at stake that matters to me. Trust is always 'a risky business' as German sociologist Niklas Luhmann claims. ${ }^{1}$ If there is nothing to lose, trust is redundant. A second important -and closely related- aspect of trust is dependency. To trust is to have positive expectations about the actions of others. These actions are important yet I cannot control them. Therefore, trust is also related to power and more particularly to power differences. When we have trust we assume that the people we are depending on will not abuse their power or hurt us. While trust is a robust strategy to deal with the inherent uncertainty in human life, it does not operate in a vacuum. The social context in which we are embedded, with its social roles, institutions, and legal frameworks, and certainly also the technologies that mediate our interactions, all influence our ability to develop trust relations. For example, social roles make the action of others more predictable and legal frameworks tell us what kind of actions are allowed and what are

DOI: 10.21552/edpl/2019/2/5

* Esther Keymolen, Assistant Professor at Tilburg University, Tilburg Institute for Law, Technology, and Society (TILT). For correspondence: <E.L.O .Keymolen@tilburguniversity.edu>.

1 Niklas Luhmann, Trust and power. Two works by Niklas Luhmann (Howard Davis tr, John Wiley \& sons Ltd 1979). 
not. Their structuring presence lowers uncertainty and can facilitate the development of trust relations.

All in all, I like to think of trust as a 'functional fiction'. It is a fiction in the sense that when we have trust, we act as if we are quite sure of what will happen, while in reality we are not. Trust is however also very functional - and therefore real - as by pretending that this one positive future state will materialise, we make social life happen.

Today, this social life to a big extent is a city life. In 2016, the UN estimated that $54.5 \%$ of the world's population lived in an urban setting. ${ }^{2}$ Cities are often densely populated and bring together a diverse public who have to find ways to organise life in a defined and shared space. Cities are therefore not a given, they are constantly being shaped and reshaped in order to enable human beings to live a flourishing life. This flourishing life entails that, with the support and respect of others, citizens are able to put key values such as autonomy, freedom, and privacy into practice. From the historic Athenian citystate (polis) - often referred to as one of the first known democracies in the world and the focal point of Plato's masterpiece The Republic - to our smart cities-in-the-making, the active involvement of citizens in creating their environment has always been of utmost importance. Active involvement here refers to more than just being a citizen afflicted with rights and duties. Active involvement is about citizens' engagement in the ongoing coshaping of the city commons - the shared resources that belong to all citizens in the city. They need to work their way through the clashes that arise when interests are conflicting, resources are scarce, and rules are unclear. In this sense, a city is always also a political community that has to deal with the urban politics brought forth by a 'being together with strangers' ${ }^{3}$ Trust plays an important role in enduring these urban social struggles. It acknowledges the vulnerability as well as the interdependency people experience when living in a shared space with strangers. Trust can facilitate active citizenship by ensuring that the open-endedness of an intersubjective life does not become overwhelming. Trust enables us to cooperate even when not all doubts are resolved and guarantees for a good outcome cannot be provided.

Now that our cities are becoming 'smart', the roles of both trust and active citizenship are changing. Smart cities are characterised by the aim to find technological, data-driven solutions to urban policy problems. There is the strong belief that through the gathering (eg sensors, cameras, apps), analysis (eg data analytics, statistical analysis, dashboards), and usage (eg automated decision-making, predictive policing) of data, it should become possible to accurately predict what is waiting for us and subsequently make the future more controllable. Whereas trust is a strategy to endure vulnerability, these data-driven solutions hold the promise to actually diminish vulnerability.

2 United Nations, Department of Economic and Social Affairs, Population Division, 'The World's Cities in 2016 - Data Booklet' (2016) ST/ESA/ SER.A/392.

3 Iris Marion Young, Justice and the Politics of Difference (Princeton University Press 1990) 264. 
In this data-driven city, active citizenship is being redefined as data-participation. Smart citizens can contribute their knowledge to the city by sharing their data with the smart city systems. The city no longer is a 'being together with strangers' but a 'being together with strangers and smart systems'. As a result, interpersonal trust increasingly has to make way for trust in technologies. This shift, however, poses some fundamental challenges to developing trust in the smart city context. First, citizens become increasingly visible in a, to them, invisible manner, a development which I earlier have called 'invisible visibility'. ${ }^{4}$ Dutch research suggests that citizens generally are not aware that there are sensors placed in the city to track their behaviour. ${ }^{5}$ Because citizens do not know how they become visible, they do not have a clear idea of what actually is at stake for them. Moreover, the 'black box' of data streams hinders citizens in appropriating the technologies in a meaningful way. Vulnerabilities closely linked to data gathering and analysis - eg loss of privacy, manipulation, discrimination- remain implicit in their daily city interactions and only seldomly become subject of a wider, political debate. Secondly, even if citizens are aware that data-driven technologies steer city life, it is not at all clear who they should turn to or hold accountable. With whom of the actors involved could they develop a trust relation if they would want to? Municipalities not only rely on large multinational companies, but also increasingly set up public-private partnerships to 'smartify' their city. On a practical level, this leads to often complicated and opaque data governance models which are difficult to scrutinise. On a normative level, this results in neo-liberal values becoming leading in the public sphere. For reasons of effectiveness and efficiency, private parties tend to choose for problems that can easily be captured through the collection of data and for solutions that are scalable and therefore more profitable. This approach not necessarily leads to addressing problems that are in line with the wishes and needs of the citizens actually living in the smart city.

All in all, where smart cities are often framed to be citizen-centric and meant to empower citizens, they actually delegate active citizenship to the smart city technologies and the actors behind it. Smart citizenship can only be active to the extent that it fits the mould of the smart city paradigm. The ongoing intersubjective and political process of shaping and reshaping city life becomes a computable task to be optimised and solved.

In a recent article $^{6}$ which I wrote together with Astrid Voorwinden, we propose, in order to counter these challenges, to put the term negotiation as a new strategy at the heart of the smart city paradigm. It should serve as 'a guiding principle for the city to reclaim itself as a place of politics where the inherent uncertainty of urban life is not dominantly regulated by control' ${ }^{7}$ As a guiding principle, negotiation refers not mere-




ly to the already existing discussions (eg between municipalities and companies), 'but to the ones that should be taking place, more specifically amongst citizens and between citizens and the municipalities' ${ }^{8}$

We identify three necessary conditions in order to make negotiation possible.

Firstly, citizens need to be recognized as subjects and not merely as data points. This implies that municipalities will need to actively go looking for the citizens behind the data doubles. They need to acknowledge that where citizens are affected in their core agency - which already quickly is the case in the city context, as some of the most important aspects of one's life, such as housing, work, education, and health, all play out on this level - they are capable of and should be allowed to participate in smart city developments in ways that exceed the current possibilities of citizen-centric initiatives.

Secondly, one cannot negotiate when it is not clear what one is negotiating about. Transparency about the smart city systems needs to be applied on three levels: one has to be open about the technology, demonstrate its functioning, and be explicit about whose interests the technology actually serves. ${ }^{9}$ The first steps have been made on this terrain by promoting open software (eg in Amsterdam and Barcelona), whereby the technology can be checked and scrutinised and has also been made available for reuse.

Finally, negotiation only works when the actors involved can understand what is at stake, not just for themselves but certainly also for the other parties involved. Vulnerability should therefore be recognised as a key aspect of city life. Because the city is first and foremost a productive, intricate, social and political community, it should be accepted that it is impossible to 'measure and control all the parameters of city life'. ${ }^{10}$ It is in particular this form of vulnerability that 'gives citizens the right to solve conflicts outside of the technological solutions: it protects the right to imagine the city differently than through the smart city paradigm'. ${ }^{11}$

Giving negotiation an explicit function in the development of smart cities might provide the much-needed impulse to pay more attention to its political nature ${ }^{12}$. In our modern, smart polis, we need to re-evaluate the position of active citizenship.

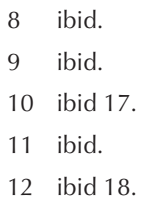

